\title{
Etika Kerja Profesional Berdasarkan 2 Korintus 2:15-16
}

\author{
oleh \\ ${ }^{* 1}$ Ezra Tari, ${ }^{* 2}$ Purnama Pasande \\ ${ }^{*}$ Sekolah Tinggi Agama Kristen Negeri Kupang \\ ${ }^{* 2}$ STT Star's Lub Luwuk Banggai \\ ${ }^{* 1}$ Alamat Korespondensi, Jl. Cak Doko No. 76 Kupang \\ Email: ${ }^{* 1}$ tariezra@gmail.com, ${ }^{* 2}$ purnama.pasande@gmail.com
}

\begin{abstract}
ABSTRAK- Penulis melakukan kajian terhadap etika kerja profesional berdasarkan 2 Korintus 2:15-16. Kajian bermula dari kerisauan penulis terhadap kondisi para pelayan dan pekerja, dimana para pelayan pada saat kurang profeional menjalankan tugas. Sehingga para pelayan tidak lagi menjadi contoh yang baik bagi masyarakat yang dilayani. Menelisik persoalan itu, penulis memaparkan tentang etika professional yang sesunguhnya bagi pelayan. Berdasarkan pembentangan yang dibuat oleh penulis, maka ada dua hal yakni melaksanakan etika kerja sesuai pekerjaan yang telah Yesus lakukan. Kedua, bekerja dengan giat. Dan menerapkan prinsip seperti Allah bekerja sampai detik ini, maka para pelayan pun bekerja juga. Oleh sebab itu, tulisan ini merupakan studi etika ptofesi dengan menekankan pada aktivitas. Bukan pada figur yang telah berhasil dalam pelayanannya.

Kata Kunci: Etika, Kerja, Profesional
\end{abstract}

ABSTRACT-The author studies the professional ethics of work based on 2 Corinthians 2: 15-16. The study stems from the writer's concern about the conditions of the servants and workers of the Lord, when they work and serve are less professional carrying out the task. So that the servants are no longer a good example for the people served. Examining the issue, the authors describe the actual professional ethics for servants. Based on the explanation made by the author, there are two things, namely carrying out work ethics according to the work that Jesus has done. Second, work hard. And applying principles like God works to this time, the servants also work. Therefore, this paper is a study of professional ethics with an emphasis on activity. Not on the figure who has succeeded in his ministry.

Keywords: Ethics, Work, Professionals

\section{PENDAHULUAN}

Penatalayanan profesional saat ini mengalami perkembangan yang pesat. Setiap pekerja akan memberikan nilai-nilai dan dampak bagi pola hidup manusia. Pola kehidupan manusia terjadi perubahan dengan adanya kebudayaan global . Teknologi informasi membantu setiap orang untuk berkomunikasi satu sama lain dengan cepat. 
Perkembangan masyarakat dari agraria ke era teknologi merubah sistim kehidupan manusia. Perubahan pemberitaan Injil dari lisan berubah menjadi digital. Pekerjan dapat dilakukan dengan media yang ada seperti twitter, facebook dan lain-lain. Media komunikasi mengubah pola hidup pelayan dan motivasi pelayan dari karir ke profesional.

Perilaku tidak profesional terjadi pada Aparatus Sipil Negara (ASN). Setelah libur idul fitri banyak ASN yang bolos. Syafruddin menilai banyaknya pegawai yang tidak hadir menandakan kepemimpinan dalam instansi kurang baik. ${ }^{1}$ Salah satu contoh absensi yang sudah masuk adalah dari Kabupaten Karangasem, Bali. Sebanyak 6.592 Aparatur Sipil Negara (ASN) di sana mangkir di hari pertama masuk kerja pasca libur Idulfitri 2019. Data Sistem Informasi Kehadiran ASN Nasional (Sidina) sampai pukul 10 WIB hari ini menunjukkan, hanya ada 44 ASN di Karangasem yang sudah menyetorkan surat keterangan, yaitu 41 orang hadir, 1 orang sakit dan 1 orang izin sementara 1 orangn lagi sedang dinas. ${ }^{2}$

Pelanggaran di atas berkaitan dengan kehadiran ASN dalam tugasnya. Tugas profesional berlaku juga bagi dosen. Bagi Einar Sitompul perubahan dari masyarakat tradisional ke era teknologi sangat cepat sehingga setiap orang mengalami goncangan budaya dan psikis. ${ }^{3}$ Kecenderungan orang pada saat ini mengikuti kemajuan yang berbenturan dengan nilai kerohanian,

1 detikNews, "MenPAN: Banyak ASN Bolos Tanda Leadership Instansi Kurang," accessed June 25, 2019, https://news.detik.com/berita/d4580967/menpan-banyak-asn-bolos-tanda-

leadership-instansi-kurang.

${ }^{2}$ Valda Kustarini, "Menpan Siapkan Sanksi Pada ASN Yang Mangkir Kerja," accessed June 25, 2019, https://kbr.id/nasional/06-

2019/menpan_siapkan_sanksi_pada_asn_yang_mang kir_kerja/99597.html.

${ }^{3}$ Einar M. Sitompul, Gereja Menyikapi Perubahan (Jakarta: BPK Gunung Mulia, 2006). 78 efesiensi, dan mencari jalan yang mudah mencapai sesuatu. Pendeta saat ini dituntut sebagai orang yang profesional yang mengerjakan pekerjaan sebagai profesi. Profesi dijalani dengan mengikuti pola organisasi di mana penekanan pelayanan pada organisasi. Pendeta seperti staf gereja yang berkantor di gereja yang ada di kota besar atau hanya mengurus persoalan organisasi gereja, administrasi gereja, sistim kepegawaian, rapat kerja tetapi melupakan tugas pokok pelayanan. Menurut E. M. Bound mengatkan bahwa pendeta bukan kaum profesional dalam pelayanannya, aktivitas pelayanan adalah kehidupan ritual rohani dan sebuah dedikasi dalam pelayanan. ${ }^{4}$ Zaman sekarang dipenuhi dengan rekayasa politik, perdagangan orang, skandal perusahaan dan manipulasi media merupakan makanan informasi orang percaya masa kini.. ${ }^{5}$ Berdasarkan latar belakang di atas, maka penulis mengindikasikan bahwa perilaku etik kerja profesional aparatur sipil negara yang di dalamnya juga ada dosen.

\section{Rumusan Masalah}

Berdasarkan latar belakang di atas, maka penulis merumuskan masalah penelitian yaitu: bagaimana etika kerja profesional dosen berdasarkan 2 kor 2:1516 di era di gital?

\section{Tujuan dan Manfaat Penelitian}

Tujuan penelitian ini adalah untuk menemukan etika kerja profesional berdasarkan 2 Korintus 2:15-16. Manfaat yang didapatkan dari hasil penelitian ini adalah: pertama mengembangkan etika kerja professional berdasarkan 2 Korintus 2:1516. Kedua dapat mengatasi permasalahan etika kerja dalam lingkup Gereja dan sosial. Ketiga menolong para pemimpin untuk

\footnotetext{
${ }^{4}$ John Piper, Brothers We Are Not Professionals (Bandung: Pionir Jaya, 2011). 15

${ }^{5}$ Joe E. Trull dan James E. Carter, op.cit, 10
} 
menerapkan etika kerja berdasarkan 1 Timotius 3:1-7.

\section{METODE}

Penulis menggunakan pendekatan kualitatif dengan jenis penelitian yang digunakan yaitu penelitian Naratif. Karena Naratif merupakan penjelasan yang bertata urut yang mengklaim sebagai rekaman peristiwa. Naratif merupakan bentuk terstruktur di mana kisah membuat penjelasan tentang bagaimana dunia ini. ${ }^{6}$

Disebutkan juga bahwa naratif berkaitan erat dengan hubungan sebabakibat dari sebuah rangkain cerita. "Narratives are based on cause-and-effect relationships that are applied to sequences of events. Metode analisis naratif dengan pendekatan teori Struktural oleh Algirdas Greimas yang memandang bahwa suatu narasi dianggap sebagai suatu struktur makna. Mirip sebuah kalimat yang terdiri atas rangkaian kata-kata, setiap kata dalam kalimat menempati posisi dan fungsinya masing-masing (sebagai subjek, objek, predikat dan seterusnya). Kata yang satu juga mempunyai relasi dengan kata yang lain sehingga membentuk kesatuan yang koheren dan mempunyai makna. ${ }^{7}$ Jadi Naratif tentunya memiliki hubungan atau relasi yang terjalin secara logis yang dihubungkan oleh keberadaan subjek dalam cerita tersebut.

PEMBAHASAN

2 Kor 2:15-16
Ay.15 Sebab bagi Allah kami adalah bau yang harum dari Kristus di tengahtengah mereka yang diselamatkan dan di antara mereka yang binasa.

Ay.16 Bagi yang terakhir kami adalah bau kematian yang mematikan dan bagi yang pertama bau kehidupan yang menghidupkan. Tetapi siapakah yang sanggup menunaikan tugas yang demikian?

Ayat 15, Di dalam Perjanjian Baru keselamatan dilukiskan sebagai (1) sudah lalu (bentuk waktu aoris: II Tim. 1:9; Tit. 3:5); (2) kini (bentuk waktu kini; di sini dan di I Kor. 1:18; 15:2); (3) masa depan (bentuk waktu akan datang: Rm. 5:9, 10; I Kor. 3:5; II Tim. 4:18); (4) sudah tercapai (bentuk waktu perfect; Ef. 2:5, 8). Kata binasa (appolumi; bdg. pemakaiannya dalam II Kor. 4:3: Yoh. 3:16 10:28; 17:12; 18:9; II Tes. 2:10) menunjukkan penghancuran dan bukan pemusnahan. ${ }^{8}$

Frasa ini memiliki dua kemungkinan latar belakang. Dalam Perjanjian Lama asap dari pengorbanan dan dupa naik kepada Allah dan diterima sebagai suatu aroma yang manis (lih. Kej 8:21; Kel 29:18,25; dalam LXX dalam Im 1:9,13,17.; 2:2; juga digunakan secara metafora oleh Paulus dalam Flp 4:18). Di abad pertama dupa dibakar di sepanjang rute parade militer Romawi masuk ke Roma. ${ }^{9}$

Ayat 16. Bau yang sama disebarkan kepada semua orang oleh para pemberita Injil. Bagi sebagian orang penyebaran itu berakibat fatal; bagi yang lain justru menghidupkan (bdg. Yoh. 3:19; 9:39; 15:22; 16:8 dst.; Kis. $\quad 13: 46$ dst.; 28:25-28).

\footnotetext{
8“2 Kor 2:15-16 - Tafsiran/Catatan - Alkitab SABDA," accessed May 31, 2019, https://alkitab.sabda.org/commentary.php?passage $=2$ +Kor+2\%3A15-16.

${ }^{9}$ Bob Utley, Komentari Alkitab Gratis, n.d., accessed May 31, 2019, http://www.freebiblecommentary.org/indonesian_bib le_study.htm.
} Praktik (Kreasi Wacana, 2008). 33

${ }^{7}$ Dedi Kurnia Syah Putra Anggraini, Cyntia Dewi; Maylanny Christin, "Analisis Struktural Naratif Algirdas Greimas Pada Artikel Storytelling Project Sunlight PT. Unilever Indonesia Pada Bulan November 2014," n.d., accessed May 31, 2019, https://openlibrary.telkomuniversity.ac.id/.../analisisstruktural-naratif-algirdas-greima. 
Peralihan dari kematian rohani (bdg. Ef. 2:1) kepada kematian abadi (bdg. Why. 2:11; 20:14; 21:8) mungkin ditunjukkan oleh bau kematian yang mematikan.Tetapi siapakah yang sanggup menunaikan tugas"Pemberitaan Injil membagi umat manusia selamanya.Dari II Kor 3:5-6 kita memahami bahwa Allah melengkapi anakanakNya untuk tanggung jawab mengagumkanuntuk bersaksi. Setiap kehidupan orang percaya adalah aroma kepada Tuhan yang membuat orang lain bereaksi,baik dalam kepercayaan terhadap Kristus atau penolakan Kristus. Sangatlah penting bagaimana kita hidup, oranglain sedang menonton (lih. 2:16; 3:2,3). ${ }^{10}$ Yesus dan para muridnya melaksanakan "praksis" dari kasih mereka kepada sesama lewat pelayanan yang diberikan kepada orangorang yang membutuhkan mereka. Segala tindakan dan karya Yesus tidak ia lakukan hanya terbatas kepada perkataan namun perbuatan. Pekerjaan menjadi sebuah hal penting yang menjadi bagian dalam keseharian Yesus. ${ }^{11}$

Bagi jiwa yang rendah hati dan penuh rahmat, pemberitaan firman teramat menyenangkan dan bermanfaat. Tis hikanos - siapayang layak mengerjakan pekerjaan yang sedemikian berat, pekerjaan yang sedemikian penting, karena dampaknya yang sedemikian besar? Siapa yang mampu melakukan pekerjaan yang begitu sulit, yang membutuhkan keterampilan dan ketekunan yang begitu besar? Pekerjaan itu berat, sedangkan kekuatan kita sedikit. Bahkan, dari diri kita sendiri, tidak ada kekuatan sama sekali. Kesanggupan kita berasal dari Allah. Perhatikanlah, jika orang betul-betul memikirkan hal-hal besar apa yang diperlukan untuk pemberitaan Injil, dan

\footnotetext{
10 Ibid.

${ }^{11}$ J.I. Packer, Ketika Yesus Bertanya Cara Pertanyaan-Pertanyaan Yesus Mengajar Dan Mentransformasi Kita (Yogyakarta: ANDI, 2010). 133
}

betapa sulitnya pelayanan Injil, maka mereka akan sangat berhati-hati bagaimana mereka masuk ke dalam pelayanan itu, dan juga sangat awas dalam menjalankannya. ${ }^{12}$

Inilah aspek profesionalisme Paulus yang perludicermati. ${ }^{13}$ Th Sumartana dalam bukunya Kemanusiaan Titik Temu AgamaAgama yang dikutip oleh penulis menetapkan tiga pola etik yakni: pertama, Yesus sebagai manusia sejati. Yesus Kristus adalah Allah yang menjadi manusia karena Ia peduli terhadap masa depan dan nasib manusia. Manusia tidak hanya percaya bahwa Allah mengutus Yesus Kristus melainkan meneladani atau melakukan kehendak Tuhan. ${ }^{14}$ Mark May mengatakan pelayan rohani tidak pernah tahu kemana mendarat pekerjaan khusus membuat mereka terpanggil untuk melaksanakannya. ${ }^{15}$ Tuntutan zaman menuntut orang Kristen bekerja dari imannya kepada Allah. Masa depan selalu rencana dan masa depan tetap terbuka. Ancaman itu terhadap spiritual absolut bagi karya kita. ${ }^{16}$

Bekerja dengan tulus, bekerja penuh integritas, bekerja dengan tanggung jawab, bekerjadengan penuh semangat, bekerja dengan penuhpengabdian, bekerja dengan kreatif, tekun danpenuh kerendahan hati memiliki pengaruhpositif terhadap kinerja kinerja karyawan baiksecara parsial dan simultan. Bukti ini akanberguna untuk manajemen yang bergerak dibidang pendidikan dan lingkungan kerja,

12"2 Kor 2:15-16 - Tafsiran/Catatan Alkitab SABDA."

${ }^{13}$ Jamin Tanhidy, "Profesionalisme Hamba Tuhan," 2017. 80

${ }^{14}$ Ezra Tari, "Tinjauan TeologisAntropologis Terhadap Peran Agama Oleh Manusia Dalam Mengembangkan Nilai-Nilai Kemanusiaan Di Era-Postmodernisme" (n.d.), accessed May 31, 2019, [PDF] dari sttjaffray.ac.id.

${ }^{15}$ Daryl Koehn, Landasan Etika Profesi (Yogyakarta: Kanisius, 2000). 44

16 John Piper, op.cit. 17 
agarmeningkatkan dan menciptakan unsur tersebutdalam melakukan pekerjaan yang terbuktimemiliki pengaruh terhadap kinerja karyawan. $^{17}$

Menurut Buchori ada tiga agenda pokok untuk menuju profesional, yaitu: pertama, program untuk menguasai kemahiran profesional. Kedua, program untuk memupuk kepekaan terhadap aspekaspek etika dari profesi. Ketiga, program untuk menanamkan dasar-dasar keberadaban. Segenap gagasan ini tergantung kepada derajat realisme dan asumsi yang dipergunakan dan kemampuan mengidentifikasikan peluang-peluang yang terdapat dalam kehidupan nyata. ${ }^{18}$ Trull dan Carter menyebutkan tiga bahaya masa kini yang dihadapi para profesional, yaitu menjadi terlalu mengandalkan diri sendiri, terlalu berorientasi pada sukses, dan terlalu yakin akan kelayakan diri sendiri terlalu yakin akan kelayakan diri sendiri. ${ }^{19}$

\section{KESIMPULAN}

Menyebarkan keharuman Kristus dengan dua cara. Pertama, melalui perkataan: menceritakan kepada orang lain tentang pribadi yang terindah. Kedua, melalui kehidupan: melakukan perbuatan

\footnotetext{
${ }^{17}$ Permata Aryana; Hery Winoto Tj., "PENGARUH BUDAYA ORGANISASI, ETIKA KERJA, DAN LOYALITAS TERHADAP KINERJA KARYAWAN (Studi Kasus Pada Karyawan Pendukung Non Akademik Universitas XYZ)Etika Kerja Kristen Pdf - Penelusuran Google" (n.d.), accessed May 31, 2019, ejournal.ukrida.ac.id/ojs/index.php/IMB/article/down load/1528/1641.

${ }^{18}$ Jannes Eduard Sirait, "PENDIDIK KRISTEN PROFESIONAL, INSPIRATIF DAN MENARIK” (n.d.), accessed May 31, 2019, http://ejournal.uki.ac.id/index.php/regulafidei.

${ }^{19}$ Yahya Wijaya, Etika Profesi Rohaniwan: Sebuah Perspektif Kristen Protestan [Etika Sosial Dalam Interaksi Lintas Agama] (Globethics.net, 2014), accessed May 31, 2019, https://www.globethics.net/gel/5728403. YahyaWijay a.
}

yang mencerminkan pengorbanan Kristus (Ef. 5:1-2). Meskipun keharuman ilahi yang kita sebarkan tidak akan dihargai oleh beberapa orang, hal itu tetap akan membawa kehidupan bagi banyak orang. Etika kerja demikianlah yang dilakukan setiap orang Kristen supaya memberikan dampak bagi banyak orang. Tugas orang Kristen di dalam dunia adalah menyebarkan bau harum dari Kristus. Dunia ini penuh dengan orang yang lelah dan sakit sehingga perlu disembuhkan. Mereka memerlukan bau harum dari Kristus untuk memberi kesegaran dan kesembuhan. Kitalah yang harus menyebarkan bau harum itu di tengah dunia ini. Orang Kristen dipanggil untuk bekerja menjadi rekan sekerja Allah dalam pembebasan dan penyelamatan alam semesta. Dasar bekerja adalah ibadah. Karena itu hakikat bekerja adalah menghayati dan mengenakan prinsip dalam Yohanes 5:17: Yesus berkata kepada mereka: "Bapa-Ku bekerja sampai sekarang, maka Aku pun bekerja juga." 


\section{DAFTAR RUJUKAN}

Anggraini, Cyntia Dewi; Maylanny Christin, Dedi Kurnia Syah Putra. "Analisis Struktural Naratif Algirdas Greimas Pada Artikel Storytelling Project Sunlight PT. Unilever Indonesia Pada Bulan November 2014," n.d. Accessed May 31, 2019. https://openlibrary.telkomuniversity.ac. $\mathrm{id} / .$. /analisis-struktural-naratifalgirdas-greima.

Aryana, Permata; Hery Winoto $\mathrm{Tj}$. "Pengaruh Budaya Organisasi, Etika Kerja, Dan Loyalitas Terhadap Kinerja Karyawan (Studi Kasus Pada Karyawan Pendukung Non Akademik Universitas XYZ)Etika Kerja Kristen Pdf - Penelusuran Google" (n.d.). Accessed May 31, 2019. ejournal.ukrida.ac.id/ojs/index.php/IM B/article/download/1528/1641.

Barker, Chris. Cultural Studies. Teori Dan Praktik. Kreasi Wacana, 2008. detikNews. "MenPAN: Banyak ASN Bolos Tanda Leadership Instansi Kurang." Accessed June 25, 2019. https://news.detik.com/berita/d4580967/menpan-banyak-asn-bolostanda-leadership-instansi-kurang.

Heryanto, Tjong. "Etika Kepemimpinan

Kristen Menjawab Tantangan Kepemimpinan Di Indonesia,” n.d. Accessed June 1, 2019. https://www.academia.edu/29017179/E TIKA_KEPEMIMPINAN_KRISTEN_ MENJAWAB_TANTANGAN_KEPE MIMPINAN_DI_INDONESIA?auto=d ownload.

Koehn, Daryl. Landasan Etika Profesi. Yogyakarta: Kanisius, 2000.

Mulyono, Yohanes Bambang. "Spiritualitas Kerja Dalam Iman Kristen | Yohanes BM Berteologi." Accessed June 1, 2019. http://yohanesbm.com/2015/12/02/spiri tualitas-kerja-dalam-iman-kristen/.
Packer, J.I. Ketika Yesus Bertanya Cara Pertanyaan-Pertanyaan Yesus Mengajar Dan Mentransformasi Kita. Yogyakarta: ANDI, 2010.

Piper, John. Brothers We Are Not Professionals. Bandung: Pionir Jaya, 2011.

Sirait, Jannes Eduard. "Pendidik Kristen Profesional, Inspiratif Dan Menarik" (n.d.). Accessed May 31, 2019. http://ejournal.uki.ac.id/index.php/regul afidei.

Sitompul, Einar M. Gereja Menyikapi Perubahan. Jakarta: BPK Gunung Mulia, 2006.

Subroto, Setyowati. "Etika, Etos Kerja Dan Sikap Professional Dalam Bisnis." Accessed June 1, 2019. https://webcache.googleusercontent.co $\mathrm{m} /$ search?q=cache:OObG5K1jrDEJ:htt ps://media.neliti.com/media/publication s/156356-ID-etika-etos-kerja-dansikapprofessional.pdf $+\& \mathrm{~cd}=3 \& \mathrm{hl}=\mathrm{id} \& \mathrm{ct}=\mathrm{cl}$ $\mathrm{nk} \& \mathrm{gl}=\mathrm{id}$.

Susanto, Magdalena Pranata. Etika Hidup Bermakna. Yogyakarta: Graha Ilmu, n.d. Accessed June 1, 2019. http://webcache.googleusercontent.com /search?q=cache:r04QLydyU14J:reposi tory.petra.ac.id/16500/1/ETIKA_2013_ MAGDA.pdf $+\& c d=9 \& h l=i d \& c t=c l n k$ $\& g l=i d$.

Suyanto, Bagong. "Superioritas Dosen Dan Posisi Tawar Mahasiswa." Berita Tagar. Last modified 2018. Accessed July 3, 2019. https://beritagar.id/artikel/telatah/superi oritas-dosen-dan-posisi-tawarmahasiswa.

Tanhidy, Jamin. "Profesionalisme Hamba Tuhan," 2017.

Tari, Ezra. "Tinjauan Teologis-Antropologis Terhadap Peran Agama Oleh Manusia Dalam Mengembangkan Nilai-Nilai Kemanusiaan Di Era-Postmodernisme" 
(n.d.). Accessed May 31, 2019. [PDF] dari sttjaffray.ac.id.

Utley, Bob. Komentari Alkitab Gratis, n.d. Accessed May 31, 2019. http://www.freebiblecommentary.org/in donesian_bible_study.htm.

Valda Kustarini. "Menpan Siapkan Sanksi Pada ASN Yang Mangkir Kerja." Accessed June 25, 2019. https://kbr.id/nasional/062019/menpan_siapkan_sanksi_pada_as n_yang_mangkir_kerja/99597.html.

Voysey, Sheridan. "Menyebarkan

Keharuman | Santapan Rohani."
Accessed May 31, 2019.

https://santapanrohani.org/2017/04/19/ menyebarkan-keharuman/.

Wijaya, Yahya. Etika Profesi Rohaniwan: Sebuah Perspektif Kristen Protestan [Etika Sosial Dalam Interaksi Lintas Agama]. Globethics.net, 2014. Accessed May 31, 2019.

https://www.globethics.net/ge1/572840 3.

"2 Kor 2:15-16 - Tafsiran/Catatan - Alkitab SABDA." Accessed May 31, 2019. https://alkitab.sabda.org/commentary.p hp?passage $=2+$ Kor $+2 \% 3$ A $15-16$. 